\title{
Periventricular pleomorphic xanthoastrocytoma (PXA) An uncommon tumor at an atypical site
}

\author{
Vinicius Trindade Gonçalves ${ }^{1}$, Fabiano Reis ${ }^{2}$, Luciano de Souza Queiroz ${ }^{3}$, Verônica de Araújo Zanardi²
}

The patient was a 15-year-old male with seizures. Diagnostic imaging demonstrated a solid-cystic expansive lesion, centered on the white matter of the left temporooccipital paratrigonal region, with growth into the ventricular system (Fig 1).

Histological analysis led to the diagnosis of pleomorphic xanthoastrocytoma (PXA) (Fig 2).

PXA is classically a tumor with a predilection for superficial growth affecting young adults, and is rarely seen in paratrigonal/intraventricular locations. The tumor in this case may have arisen in and around the ventricle or from subcortical white matter.

The patient has now been followed for ten years. The tumor recurred after five years without anaplastic transformation. He appears to be free of disease at present.

\section{REFERENCES}

1. Crespo-Rodriguez AM, Smirniotopoulos JG, Rushing EJ. MR and CT imaging of 24 pleomorphic xanthoastrocytomas (PXA) and a review of the literature. Neuroradiol 2007;49:307-315.

2. Fu YJ, Miyahara H, Uzuka T, et al. Intraventricular pleomorphic xanthoastrocytoma with anaplastic features. Neuropathol 2010;30:443-448.

3. Giannini C, Scheithauer BW, Burger PC, et al. Pleomorphic xanthoastrocytoma: what do we really know about it? Cancer 1999;85:2033-2045.

4. Kepes JJ, Rubinstein U, Eng LF. Pleomorphic xanthoastrocytoma: a distinctive meningocerebral glioma of young subjects with relatively favorable prognosis. Cancer 1979;44:1839-1852.

5. Koeller KK, Henry JM. From the archives of the AFIP: superficial gliomas: radiologic-pathologic correlation. RadioGraphics 2001;21:1533-1556.

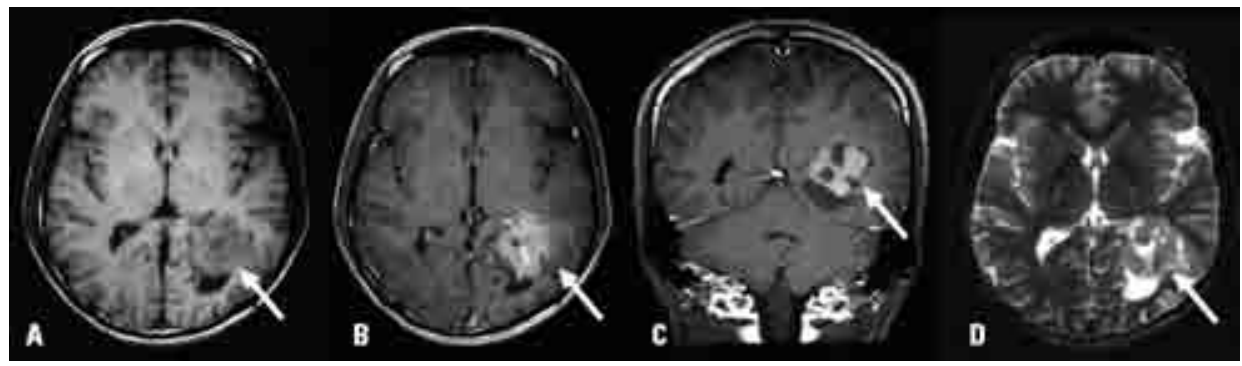

Fig 1. [A] Axial T1 weighted image (WI) demonstrating a left temporo-occipital lesion of low to isointensity. Axial [B] and coronal [C] T1 WI after gadolinium showing a heterogeneously enhanced lesion. [D] Axial T2 WI demonstrating iso to high intensity of the lesion.

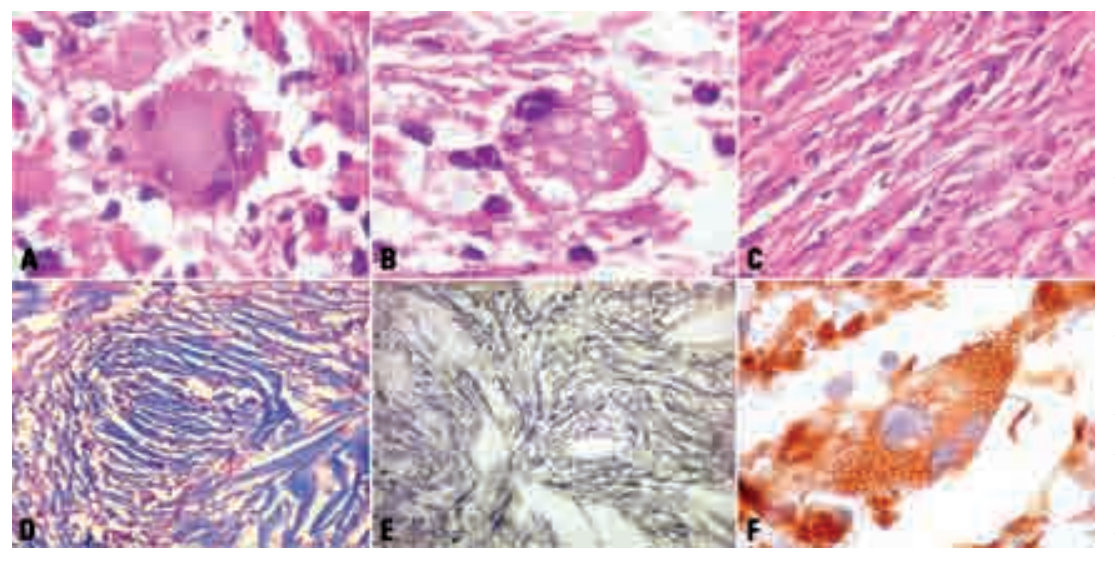

Fig 2. [A] Multinucleated tumor cell featuring prominent nuclear atypia and abundant eosinophilic cytoplasm, reminiscent of gemistocytic astrocytes. [B] Aberrant cell with numerous cytoplasmic vacuoles, possibly containing lipids. [C] Large areas of tumor formed by spindle cells in bundles, often with large hyperchromatic nuclei. [D] Masson's trichrome staining, revealing thick collagen fibers among the tumor cells. [E] Reticulin fibers distributed at sites similar to those of collagen fibers. [F] A xanthomatous three-nucleated tumor cell with cytoplasmic positivity for GFAP (glial fibrillary acidic protein), thus demonstrating its astrocytic lineage.

\section{XANTOASTROCITOMA PLEOMÓRFICO PERIVENTRICULAR: UM TUMOR INCOMUM EM LOCALIZAÇÃO ATÍPICA}

Clinics Hospital, School of Medical Sciences, State University of Campinas, Campinas SP, Brazil: ${ }^{1}$ Medicine Student, Department of Radiology; ${ }^{2} \mathrm{MD}$, PhD, Professor of the Department of Radiology; ${ }^{3} \mathrm{MD}$, PhD, Professor of the Department of Pathology.

Correspondence: Fabiano Reis - Departamento de Radiologia, Faculdade de Ciências Médicas, Universidade Estadual de Campinas - Rua Tessália Vieira de Camargo 126 - CP 6111 - Cidade Universitária Zeferino Vaz - 13083-887 Campinas SP - Brazil. E-mail: fabianoreis2@gmail.com

Support: VT Gonçalves receive financial support by FAPESP

Received 28 January 2011. Received in final form 17 February 2011. Accepted 24 February 2011. 